\title{
EFFECT OF VARIOUS PHYSICAL THERAPY PROGRAMS ON THE QUALITY OF LIFE, BALANCE, KINEMATICS OF SPEED AND ACCURACY MOVEMENTS OF THE HAND IN PATIENTS WITH PARKINSON'S DISEASE
}

\author{
Dalia Mickevičiene் ${ }^{1}$, Indrè Skirmantaité $\dot{2}^{2,3}$, Neringa Švedaité $\dot{e}^{4}$, \\ Aiva Karpavičienè $\dot{1}^{1}$ Lina Danilevičienè ${ }^{1}$ \\ Lithuanian Sports University', Kaunas, Lithuania \\ Šiauliai State College ${ }^{2}$, Šiauliai, Lithuania \\ Mykolas Romeris University ${ }^{3}$,Vilnius, Lithuania \\ Druskininkai Hospital', Druskininkai, Lithuania
}

\begin{abstract}
Research background and hypothesis. Parkinson's disease is a relevant health problem in the way that the disease limits human movement to a great extent as well as degrades the quality of life and overall communication capabilities. We believe that by accelerating the pace of individual workouts on the treadmill in the gym, better results will be achieved than using individual physical therapy at home.

Research aim was to determine the effectiveness of various physical therapy programs on the quality of life, balance and kinematics of speed and accuracy movements of the hand in patients with Parkinson's disease.

Research methods. First group $(\mathrm{n}=12)$ had individual physical therapy in the weightlifting gym. The second group $(\mathrm{n}=12)$ had individual physical therapy at home. For the assessment of the quality of life, we selected the questionnaire PDQ-39 (Parkinson's Disease Questionaire-39), and the subjects filled it in independently. For the assessment of static and dynamic balance, Berg Balance Scale and balance confidence scale were applied. Walking speed was assessed by using the "Up and go" test. The original device developed by Lithuanian Sports University researchers and Ltd. Katra specialists - the dynamic parameter analyser of human arm and leg movements DPA-1 was used to evaluate the characteristics of the kinematics of the dominant arm movement.

Research results. It was found that after 16 physiotherapy procedures, the quality of life statistically significantly improved in all eight areas $(\mathrm{p}<0.05)$ in both groups under investigation. Mean Berg Balance Scale values after 16 physiotherapy procedures statistically significantly increased $(\mathrm{p}<0.05)$ in Group I and Group II. A statistically significant improvement in balance $(\mathrm{p}<0.05)$ was found in both groups. There was a statistically significant decrease $(p<0.05)$ in the test performance average time values of "Up and go" test in both groups. A statistically significant increase $(p<0.001)$ was established in the mean values of the six-minute walk distance. Kinematics of speed and accuracy movements statistically significantly increased $(\mathrm{p}<0.05)$ in both groups.

Discussion and conclusions. Both physical therapy programmes were effective in improving the quality of life, balance and kinematics of speed and accuracy movements of the hand in patients with Parkinson's disease. Individual physical therapy programme at home was less effective, while acceleration of the pace of individual workouts on the treadmill in the gym had a greater impact.
\end{abstract}

Keywords: Parkinson's disease, quality of life, motor control, physical therapy, reaction time, complexity of task.

\section{INTRODUCTION}

$\mathrm{P}$ arkinson's disease is a chronic progressive neurodegenerative disease characterized by motor symptoms of the triad: resting tremor,

bradykinesia and rigid muscles because of the lack of dopamine in extrapyramidal system (Weintraub et al., 2008; Hass et al., 2010; McNeely, Earhart, 2012). 
Parkinson's disease is one of the most common progressive, degenerative, incurable diseases that affects the human nervous system (Tomlison et al., 2012).When birth and death ratio changes, changes in the population age structure emerge. The number of aging and old people is increasing (Daugèlienè, Tamošiūnas, 2007). Parkinson's disease is a disease of older people and thus, the likelihood of developing the disease increases. Even 6.3 million people in the world suffer from Parkinson's disease. According to the data of Lithuanian Institute of Hygiene Health Information Centre, in 2010, 10757 people in Lithuania suffered from Parkinson's disease. This is a relevant health problem as the disease limits human movements, degrades the quality of life and fullrate communication potential. Many people with Parkinson's disease require extensive rehabilitation application as sufferers face problems that are not fully controlled by medication: disorders of balance, mobility, activities of daily living, cognition, language, sleep as well as dysphagia, depression and fatigue. In spite of optimal pharmacological treatment motor functions progressively deteriorate, reducing patients' mobility, self-care, communication, and participation in the social environment. Physical therapy sessions are very important for patients with Parkinson's disease as they have a positive impact on patients' motor function and the quality of life, which vary with the progression of the disease (Filippin et al., 2010; Earhart, Williams, 2012). N. Filippin et al. (2010) argue that physical therapy is an effective non-pharmacological treatment which has a positive effect on mobility, daily activities and the quality of life for patients with Parkinson's disease.

The aim of the research was to determine the influence of various physical therapy programs on the quality of life, balance and kinematics of speed and accuracy of the hand in patients with Parkinson's disease. Our hypothesis is that by accelerating the pace of workouts on the treadmill, we will achieve better results than by using individual physical therapy at home.

The object of the research was changes in the quality of life, balance, kinematics of speed and accuracy movements of the hand.

\section{RESEARCH METHODS}

The patients were selected according to the modified M. M. Hoehn and M. D. Yahr scale (1967) with stages 1 and 2. The criteria for patient selection were the following:

1. Patients diagnosed with idiopathic Parkinson's disease;
2. Patients with stages 1 and 2;

3. The symptoms started on the right side of the body (damaged right side of the body);

4. The dominant arm - right;

5. The voluntary consent to participate in the study.

The criteria according to which the patients were not included in the research were as follows: the patients with Parkinson's disease who had severe concomitant diseases, disturbing movement or causing disability and significantly degrading the quality of life (stroke, osteoarthritis, the state after the endoprosthesis, rheumatoid arthritis).

The total sample consisted of 24 patients who were randomly divided into two groups: 12 females and 12 males. The patients were selected according to the modified M. M. Hoehn and M. D. Yahr (1967) stages scale, with 1-2 disease stages. Group I: 6 females and 6 males, age $63.13 \pm 9.08$ years, body mass $78.50 \pm 12.14 \mathrm{~kg}$, height $173.25 \pm 10.50$ $\mathrm{cm}$ and duration of the disease $-5.56 \pm 2.13$ years. Group II: 6 females and 6 males, age $65.63 \pm 7.42$ years, body mass $74.20 \pm 10.83 \mathrm{~kg}$, height $170.80 \pm$ $5.89 \mathrm{~cm}$ and duration of the disease $-5.81 \pm 3.32$ years.

The subjects were tested twice: before and after a 4-week course of physiotherapy procedures. Physical therapy was applied four times a week. The duration of one procedure was 45 minutes. In the first group individual physical therapy procedures were performed by accelerating the pace of workout on the treadmill in weightlifting gym of Lithuanian Sports University, while the subjects in the second group had individual physical therapy sessions at home. Individual physical therapy at home was performed with gymnic balls, unstable platforms, sticks, theraband elastic bands and stepping exercises (15 minutes). Procedures were carried out in a steady rhythmic audio stimulation - giving orders, clapping and counting. Metronome and music were used in all procedures.

For the assessment of the quality of life the questionnaire PDQ-39 (Parkinson's Disease Questionnaire-39) was used. The following eight aspects were studied: mobility, daily living activities, emotions, disgrace, social support, cognitive function, communication, physical discomfort.

Berg Balance Scale was used for the assessment of static and dynamic balance. The tasks were grouped into static and dynamic to research the patients when sitting and standing as well as marching on the spot. For the assessment of 
balance, Balance Confidence Scale was used. The "Up and Go" test was used to assess the walking speed, which is very often used in clinical studies as it is quick and easy to perform and does not require special equipment or performing skills. In order to perform the test a standard chair with a backrest and a stopwatch to capture test execution speed (in seconds) were used. The main feature of this test is that it consists of a number of trunk control and gait quality reflecting tasks: standing up from a chair, 3 meters walking straight, turning without losing balance, returning to the chair, spinning around its own axis and sitting down. The time for performing the test is assessed (Morris et al., 2006).

The study of reaction time and movement kinematics. The original device developed by Lithuanian Sports University researchers and Ltd. Katra specialists - the dynamic parameter analyser of human arm and leg movements DPA-1 - was used for the research. The right arm movement reaction time (RT) was recorded as well as the right arm maximum velocity (Vmax) at performing the tasks for reaction, speed and accuracy.

Functional assessment of the body capacity. The 6-minute walk test, which evaluates the overall body and individual systems' response to exercise (American Thoracic Society). The test measured the 6-minute walk distance across a long, smooth, straight corridor. The study was carried out according to the standard protocol - a walk distance in the corridor was marked and walk duration was measured with a stopwatch. Besides, the subjects' heart rate and arterial blood pressure using a blood pressure machine OMRON M3 were measured before and after the test.
Mathematical Statistics. Statistical data analysis was performed using SPSS 21.0 for Windows and Microsoft Office Excel 2010 statistical package. Depending on the data sample, mean values, standard deviations were calculated, the sample sizes were compared with Student's t-test, Chi-square and Wilcoxon and KruscalWallis tests. Statistically significant differences were recorded at $\mathrm{p}<0.05$.

\section{RESEARCH RESULTS}

The results of the research revealed that after 16 physical therapy procedures the quality of life significantly improved in Group I and Group II in all eight areas of the quality of life $(\mathrm{p}<0.05)$.

Mean Berg Balance Scale value after 16 procedures statistically significantly increased $(\mathrm{p}<0.05)$ : in Group I - from $41.25 \pm 2.38$ points to $52.38 \pm 1.41$ points, in Group II $-40.00 \pm 2,07$ points to $49.75 \pm 2.12$ points (Figure 1).

Balance scale results in Group I before and after physical therapy improved by $16.07 \%$. A statistically significant improvement was observed in balance $(\mathrm{p}<0.05)$. Balance scale results in Group II before and after physical therapy improved by $20.52 \%$. A statistically significant improvement was established in balance $(\mathrm{p}<0.05)$.

The test performance average time values in the "Up and go" test statistically significantly decreased in both groups $(p<0.05)$ (Figure 2).

A statistically significant increase was found in the average values of walk distance in both groups ( $\mathrm{p}<0.001)$ after physical therapy sessions (Figure 3). Comparison of both groups revealed statistically significant differences in the average values of walk distance $(\mathrm{p}<0.001)$
Figure 1. Mean Berg Balance Scale value in Group I and Group II before and after physical therapy
Note. ${ }^{*}-\mathrm{p}<0.05$, comparing the results before and after physical therapy in different groups.

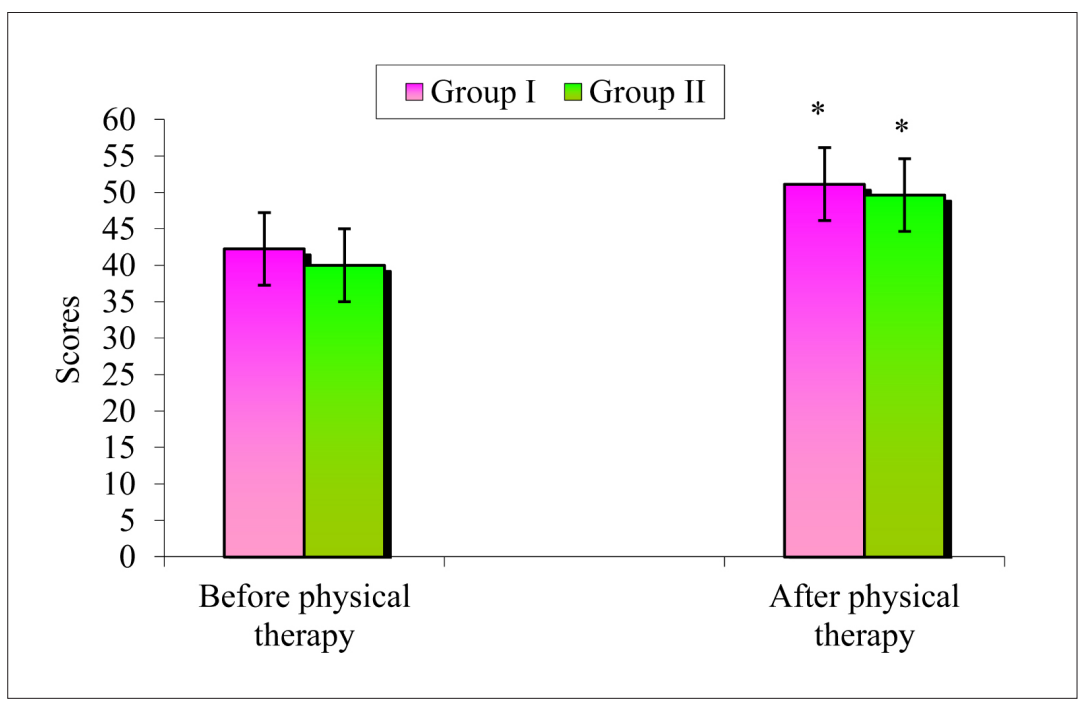



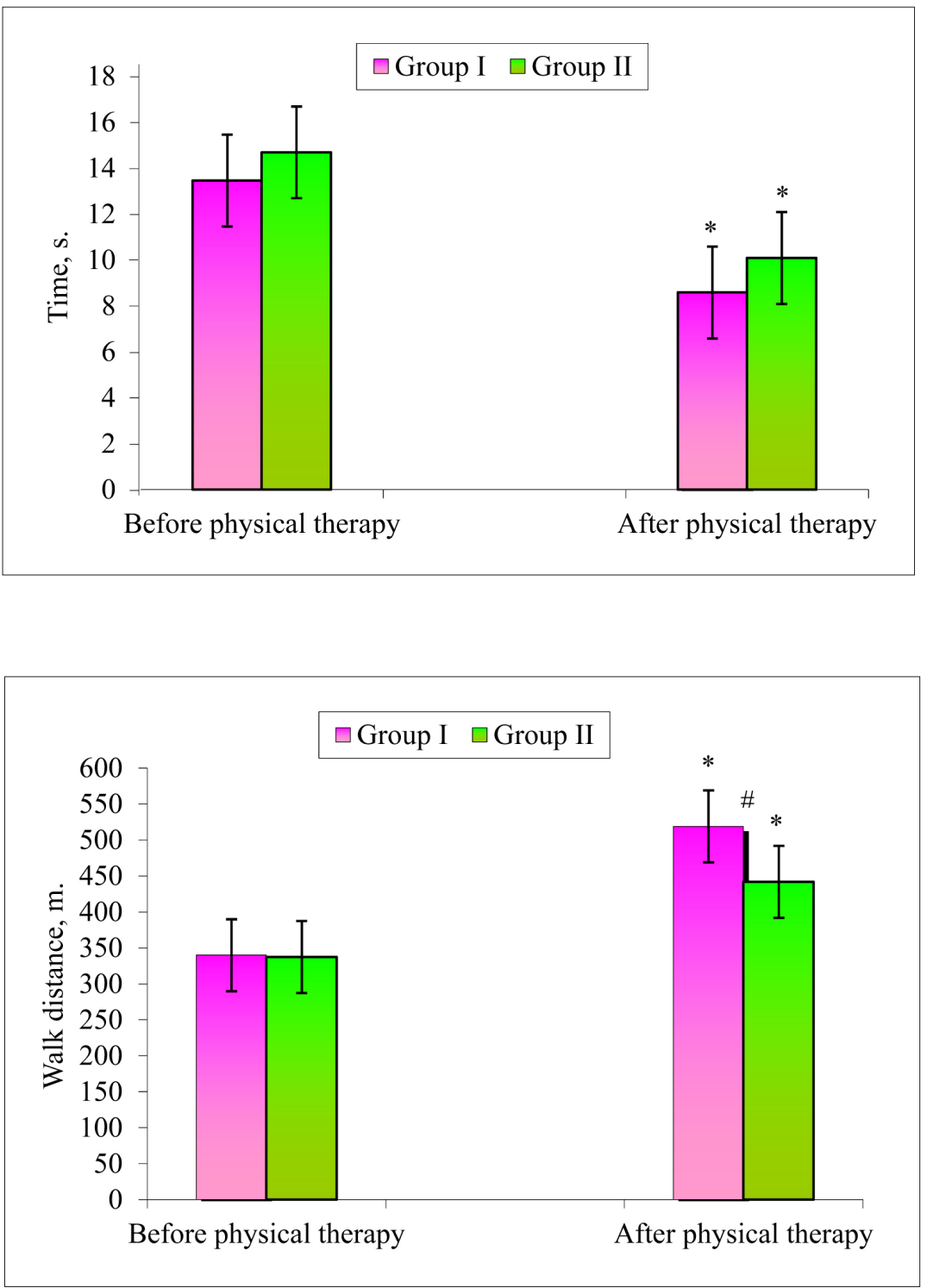

Figure 2. Test performance average time values in the "Up and go" test before and after physical therapy

Note. $*-p<0.05$, by comparing the results before and after physiotherapy.

Figure 3. The 6-minute walk distance in meters before and after physical therapy in Group I and Group II

Note. ${ }^{*}-\mathrm{p}<0.001$, by comparing results before and after physical therapy in different groups; $\#-\mathrm{p}<0.05$, for comparison of the results between the groups.
At the end of the study simple and complex task reaction time average in Group I statistically significantly improved $(\mathrm{p}<0.001)$ and was $266 \pm 58 \mathrm{~ms}$ (a simple task), and $278 \pm 49 \mathrm{~ms}$ (a complex task). Simple and complex task reaction time average in Group II showed a statistically significant improvement $(\mathrm{p}<0.001)$ and was $248 \pm$ $53 \mathrm{~ms}$ (a simple task) and $286 \pm 76 \mathrm{~ms}$ (a complex task).

Performing a simple task, when after hearing the sound the subjects had only to push the device handle, the maximum speed change statistically significantly improved only in Group I $(p<0.05)$ when results were compared before and after 16 physical therapy procedures.

Performing 5 series of the task after 20 repetitions in Group I, there was a statistically significant improvement $(\mathrm{p}<0.001)$ in all 5 task series when the results before and after physical therapy were compared. A statistically significant improvement $(p<0.05)$ in Group II was established only in the first, second, third and fourth series.

Time to target average indices statistically significantly improved $(\mathrm{p}<0.001)$ in both groups.

\section{DISCUSSION}

The hypothesis that physical therapy by accelerating the pace of individual workouts on the treadmill is more effective than physical therapy at home in the attempt to improve the quality of life, balance and kinematics of speed and accuracy movements of the hand in patients with Parkinson's disease was tested in the study.

The research revealed that both physical therapy programs after 16 procedures statistically 
significantly increased the subjects' 6-minute walk distance. However, comparison of the two groups revealed that the average value in the 6-minute walk distance (by accelerating the pace of individual workout on treadmill) in Group I was statistically significantly higher than in Group II (physical therapy at home). G. Frazzitta et al. (2010) study shows that after the application of a 4-week physiotherapy, there was a statistically significant improvement in the gait and the 6-minute walk test results. Our results coincide with those carried out by the authors of the study.

Our study shows that physical therapy program by accelerating the pace of individual workout on the treadmill as well as individual physical therapy at home are effective for patients' with Parkinson's disease quality of life. When comparing the results before and after physical therapy in both groups statistically significantly higher levels were established in all areas of the quality of life. The comparison of the results in both groups revealed that the quality of life after physical therapy in all areas was evaluated higher by the subjects of Group I, however, statistically significant difference was not observed between the groups.

The research shows that the quality of life deteriorates only at the beginning of the disease. Those patients who have been suffering from Parkinson's disease for 5-9 years evaluate the quality of life in all areas much worse than those who have been suffering from this disease from 0.5 to 4 years (Valeikiene,, Juozulynas, 2006). The subjects in Group I have been suffering from Parkinson's disease on average for $5.56 \pm 2.13$ years, while the subjects in Group II have been diagnosed in the disease for $5.81 \pm 3.32$ years. It was found that the quality of life before physical therapy was rated similarly by the subjects of both groups in all areas and statistically significant differences were not established. It was found that before physical therapy the worst quality of life was found in mobility and daily living activities. Results of our research coincide with the study carried out by V. Valeikiene et al. (2009) which showed that the worst quality of life among patients with Parkinson's disease was found in mobility and daily living activities.

Our study proves that both physical therapy programs were effective for developing balance in patients with Parkinson's disease. Improvement in static and dynamic balance was observed after physiotherapy in both groups. Analysis of static and dynamic balance changes showed that statistically significant differences were established after physical therapy in both groups. By applying the accelerating pace of workouts on the treadmill in Group I, static and dynamic balance increased by 11.13 points, while in the case of individual physical therapy at home in Group II, static and dynamic balance increased by 9.75 points. The research data show that static and dynamic balance increased more effectively when physical therapy by accelerating the pace of individual workout on treadmill was applied to the subjects, but statistically significant differences were not found. Similar improvements in the balance after 4 weeks of physical therapy were observed by G. Frazzitta et al. (2010). The results of their research indicate that the Berg Balance Scale score after physical therapy improved by $21 \%$.

The results of our research suggest that both physical therapy programs are effective in training movement accuracy and speed for patients with Parkinson's disease. The speed and accuracy of movement after 16 procedures of physical therapy significantly improved.

The research carried out by E. Dereli and A. Yaliman (2010) suggests that physical therapy treatment at home under supervision of a physiotherapist is more effective than self-guided physical therapy programs at home. Our research has determined that physical therapy program by accelerating the pace of individual workout on the treadmill and individual physical therapy program at home are effective in treating patients with Parkinson's disease.

Comparison of the effect of two physical therapy programs on the quality of life, balance, kinematics of speed and accuracy of the hand in patients with Parkinson's disease, allows us to confirm our hypothesis. Both physical therapy programs were effective for the quality of life, balance, kinematics of speed and accuracy of the hand in patients with Parkinson's disease. Individual physical therapy program at home was less effective, while physical therapy program by accelerating the pace of individual workout on treadmill in the gym had a greater impact on patients with Parkinson's disease.

\section{CONCLUSIONS AND PERSPECTIVES}

1. After physical therapy procedures, a statistically significant improvement in the quality of life, balance, kinematics of speed and accuracy of the hand was found in the subjects who received physical therapy treatment at home. 
2. After physical therapy procedures a statistically significant improvement in the quality of life, balance, kinematics of speed and accuracy of the hand was found in the subjects who received physical therapy treatment by accelerating the pace of individual workouts on the treadmill in the gym.
3. The subjects of the research, who received physical therapy treatment by accelerating the pace of individual workouts on the treadmill in the gym, rated the quality of life higher, better managed the rapid and accurate movements of the hand and were capable of keeping a more stable balance.

\section{REFERENCES}

Daugèlienè, E., Tamošiūnas, A. (2007). Pagyvenusio amžiaus žmoniu skaičiaus augimas bei ju sveikatos ypatybès. Lietuvos bendrosios praktikos gydytojas, XI (6), 420-424.

Dereli, E. E., Yaliman, A. (2010). Comparison of the effects of a physiotherapist-supervised exercise programme and a self-supervised exercise programme on quality of life in patients with Parkinson's disease. Clinical Rehabilitation, 24 (4), 352-362.

Earhart, G. M., Williams, A. J. (2012). Treadmill training for individuals with Parkinson disease. Physical Therapy, 92 (7), 893-897.

Filippin, N., Paula, H., Costa, L., Mattioli, R. (2010). Effects of treadmill-walking training with additional body load on quality of life in subjects with Parkinson's disease. Revista Brasileira de Fisioterapia, 14 (4), 344-350.

Frazzitta, G., Maestri, R., Bertotti, G. et al. (2010). Rehabilitation in Parkinson's disease: Assessing the outcome using objective metabolic measurements. Movement Disorder, 15, 25 (5), 609-614.

Hass, V. B., Klassen, L., Sheppard, S., Metcalfe, A. (2010). Psychometric properties of activity, self-efficacy, and quality-of-life measures in individuals with Parkinson disease. Physiotherapy Canada, 63 (1), 47-57.
Hoehn, M. M., Yahr, M. D. (1967). Parkinsonism: Onset, progression, and morality. Neurology, 17, 427-442.

McNeely, M., Earhart, G. (2012). Lack of short-term effectiveness of rotating treadmill training on turning in people with mild-to-moderate Parkinson's disease and healthy older adults: A randomized, controlled study. Parkinson's Disease, 41-8.

Morris, E. M. (2006). Locomotor training in people with Parkinson's disease. Physical Therapy, 86 (10), 1426-1435.

Tomlison, C., Patel, S., Meek, C. et al. (2012). Physiotherapy intervention in Parkinson's disease: Systematic review and meta-analysis. BMJ (Clinical Research ed.), 345, 1-14.

Valeikiene, V., Juozulynas, A., Alekna, V. (2009). Parkinsono ligos medikamentinis gydymas ir tiesioginès medicininès išlaidos. Sveikatos mokslai, 1, 2197-2200.

Valeikienè, V., Juozulynas, A. (2006). Gyvenimo kokybė sergant Parkinsono liga. Gerontologija, 7 (2), 78-87.

Weintraub, D., Comella, C., Horn, S. (2008). Parkinson's disease - part 1: Pathophysiology, symptoms, burden, diagnosis, and assessment. American Journal of Management Care, 14, 40-48. 